\title{
The Treatment of Post-Thrombotic Syndrome
}

The Role of Endovascular Recanalization in Chronic lliac Vein Obstruction

Karina Schleimer, Mohammad Esmaeil Barbati, Alexander Gombert,

Volker Wienert, Jochen Grommes, Houman Jalaie

\section{SUMMARY}

Background: Post-thrombotic syndrome (PTS) arises in $20-50 \%$ of patients who have sustained a deep vein thrombosis and markedly impairs their quality of life.

Methods: This review is based on pertinent publications retrieved by a selective literature search in PubMed and the Cochrane Library, and on the guidelines of the German Societies of Phlebology and Vascular Surgery (Deutsche Gesellschaft für Phlebologie, Deutsche Gesellschaft für Gefässchirurgie).

Results: The treatment options are conservative treatment with compression and patient exercises, endovascular recanalization with stent angioplasty, and open bypass surgery of the iliac obstructions. The endovascular techniques yield patency rates of 73 to $100 \%$, with thrombotic stent occlusion and hematoma as potential complications. The open operations have only been documented in studies with small case numbers ( 3 to 85 cases per study, patency rates 58 to $100 \%$ ). The complications of these invasive procedures can include thrombotic bypass occlusion, hematoma, and wound infection. There have been randomized trials of conservative treatment, but not of surgical treatment. The American Heart Association, in its guidelines, gives the same weak recommendation for all surgical methods (llb).

Conclusion: All conservative options should be exhausted as the first line of treatment. If PTS symptoms persist and markedly impair the patient's quality of life, the possible indication for surgery should be considered. As PTS hardly ever leads to death or limb loss, its treatment should be as uninvasive as possible. Endovascular recanalization is an attractive option in this respect. A conclusive evaluation of the role of endovascular procedures in PTS must await randomized trials of this form of treatment and of the optimal stent configuration.

\section{- Cite this as:}

Schleimer K, Barbati ME, Gombert A, Wienert V, Grommes J, Jalaie H: The treatment of post-thrombotic syndrome-the role of endovascular recanalization in chronic iliac vein obstruction.

Dtsch Arztebl Int 2016; 113: 863-70. D0I: 10.3238/arztebl.2016.0863
University Hospital Aachen: PD Dr. med. Schleimer, Barbati, M.D., Dr. med. Gombert, Prof. Dr. med. Wienert, PD. Dr. med. Grommes, Dr. med. Jalaie $n$ about $20 \%$ to $50 \%$ of patients in whom a deep vein thrombosis has been diagnosed, a postthrombotic syndrome follows. This remains the case even when appropriate anticoagulation treatment has been given $(1,2)$.

In the pathogenesis of postthrombotic syndrome, venous hypertension plays a central role. Incomplete spontaneous recanalization leads to chronic venous obstruction. Venous wall fibrosis and damaged venous valves cause reflux. All this leads to venous hypertension. Venous hypertension in turn causes dilatation of the capillaries and increased endothelial permeability to plasma, proteins, and erythrocytes. Consequences include edema, inflammation, hyperpigmentation of the skin, and eczema or even the development of a venous ulcer. In addition to all of this, venous hypertension causes distension of the deep veins with an increase in valvular incompetence, which is then transmitted to the superficial venous system via the perforating veins (secondary varicosis) (3, e1-e3).

Typical symptoms are: heaviness and tension, itching, cramp, and pain. Venous claudication occurs in the form of a bursting pain during walking, which eases during standing or when the affected leg is raised up (e1).

Clinical signs include phlebedema, venous ectasia, collateralization, stasis dermatitis, hyperpigmentation, atrophie blanche, dermatolipofasciosclerosis, and venous ulcer. Dermatolipofasciosclerosis leads to restriction of movement in the ankle (arthrogenic stasis syndrome). Because of this, the calf muscle pump ceases to be sufficiently activated, thus further reinforcing the vicious circle of venous hypertension (4, e1) (Figure 1).

Postthrombotic syndrome greatly impairs patients' quality of life and has considerable socioeconomic consequences. In the USA, the average yearly costs for these patients are estimated at about USD 20500 per patient $(1,5)$.

Postthrombotic syndrome is diagnosed on the basis of the symptoms and signs mentioned above. Special scoring systems have been developed (e.g., Villalta, Ginsberg, and Brandjes scores), which assign point scores to the symptoms and signs according to their severity (6-8, e3). The primary diagnostic imaging technique used is duplex ultrasonography. If iliac/caval 
Figure1:

Clinical signs of postthrombotic syndrome

a) venous leg ulcer b) venous collaterals
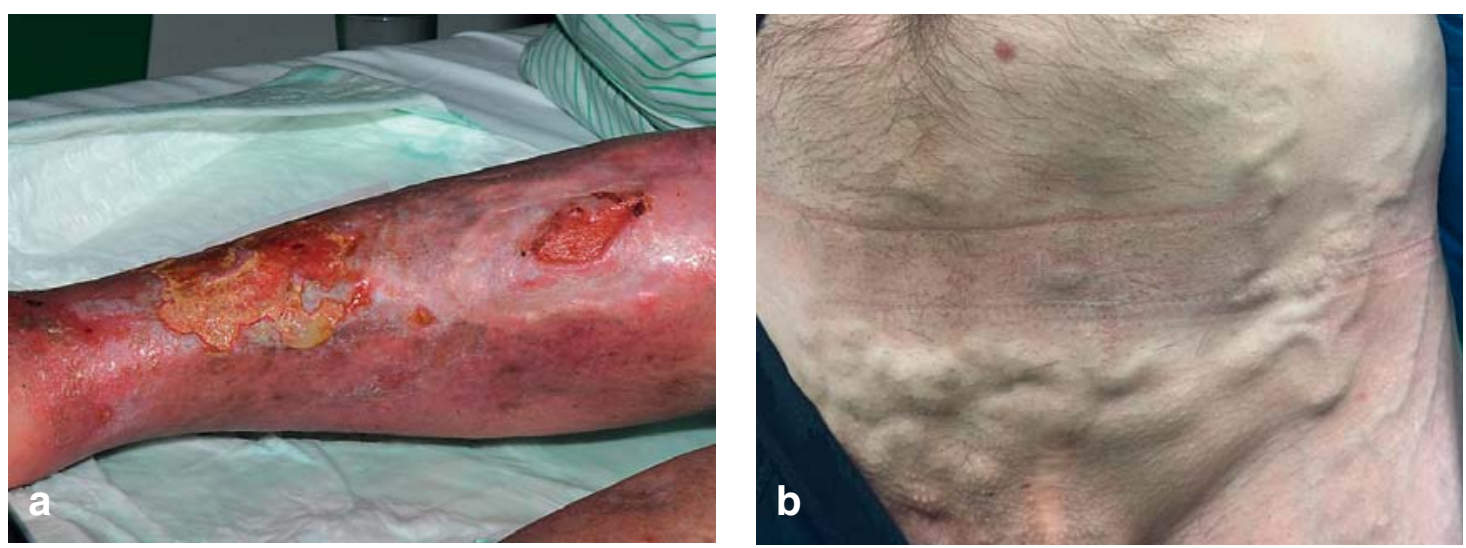

obstructions are suspected, computed tomographic (CT) or magnetic resonance (MR) venography aids further clarification. Gadolinium-enhanced MRvenography is particularly well suited to reliable detection of intraluminal trabeculae and vascular wall thickening (9).

The location and extent of the initial deep vein thrombosis are the most important predictors of the occurrence of postthrombotic syndrome (2, e4-e7). For example, deep vein thrombosis of the iliac veins or of the common femoral vein (CFV) carries a significantly higher risk of postthrombotic syndrome than a popliteal or crural deep vein thrombosis (risk ratio 2.3 ; 95\% confidence interval $[95 \% \mathrm{CI}]$ : $[1.0 ; 5.6](10)$. Where the deep vein thrombosis occurs in iliac veins, 2 years later residual thrombi are present in $33 \%$ of cases, whereas thrombi in distal venous segments have resolved more completely (3\% residual thrombi after 2 years) (10). In one study, Kahn et al. showed that iliac location of a deep vein thrombosis was the strongest risk factor for the development of severe postthrombotic syndrome (11). Other risk factors include:

- Advanced age

- Obesity

- Subtherapeutic INR values during treatment for deep vein thrombosis $(1,2,12$, e4).

The aim of this article is to provide an up-to-date overview of treatment for postthrombotic syndrome, with a particular emphasis on the role of endovascular recanalization. Prevention of postthrombotic syndrome is not covered in this article.

\section{Methods}

This review is based on a selective literature search of the PubMed database, the Cochrane Library, and the guidelines of the German Society of Phlebology (Deutsche Gesellschaft für Phlebologie) and the German Society of Vascular Surgery (Deutsche Gesellschaft für Gefässchirurgie). The search terms used were "postthrombotic syndrome," "post-thrombotic syndrome," and "postthrombotisches Syndrom." From the search results, we selected those publications relating to the treatment of postthrombotic syndrome. Case reports, (animal) experimental studies, and articles on postthrombotic syndrome of the upper extremity or in children were excluded.

\section{Conservative treatment of postthrombotic syndrome}

The goal of treatment for postthrombotic syndrome is symptomatic relief, since the condition itself is not curable. Compression therapy is used, the effects of which include the following:

- Reducing the diameter of the vein and hence improving venous valvular function,

- Accelerating venous backflow, and

- Preventing and reducing leg edema $(6,13,14)$.

Only two small randomized studies have been published on the treatment of postthrombotic syndrome with medical compression stockings ( $n=115$ patients). These studies did not show any advantage from the wearing of compression stockings $(7,15)$ - a finding, however, that does not accord with clinical experience.

Although the Cochrane Review of 2003, which included the study by Ginsberg et al., does not recommend compression stockings to treat postthrombotic syndrome $(7,16)$, the American Heart Association (AHA) supports a weak recommendation because of their low side effects (allergic skin reaction) and possible utility (especially, edema reduction), so long as any contraindications have been excluded (e.g., advanced peripheral arterial occlusive disease, decompensated heart failure) (recommendation class IIb, evidence level C (17). According to the current guidelines of the German Society of Phlebology (DGP), compression stockings improve subjective venous symptoms; especially, leg edema is reduced (evidence level A) (13). In their most recent publication on the treatment of postthrombotic syndrome, Kahn et al., whose SOX study showed no advantage of compression stockings in preventing postthrombotic 


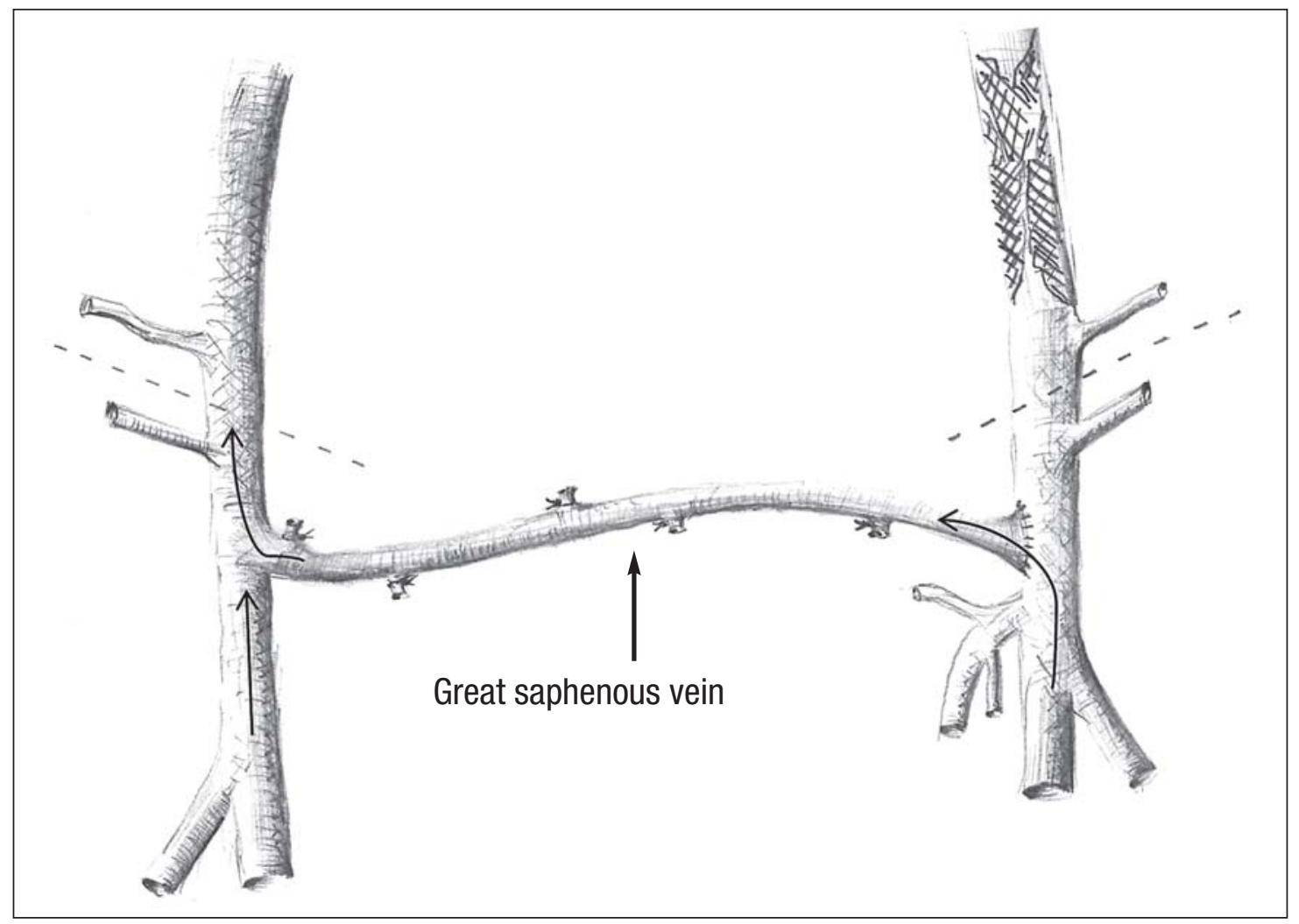

Figure 2: Femoral crossover bypass as described by Palma and Esperon

syndrome, recommend the wearing of knee-high compression stockings (20 to $30 \mathrm{mmHg}$ ), and that the compression pressure can be increased up to 40 to 50 $\mathrm{mmHg}$ if needed $(1,18)$.

The evidence in the literature for the use of compression stockings in treatment of venous ulcer is clearer. Seven studies have shown that chronic venous ulcers heal more quickly with compression than with wound care without compression. Compression stockings are therefore recommended both in the DGP guidelines and those of the AHA (recommendation class I, evidence level A) $(13,17,19)$.

According to the DGP guidelines, intermittent pneumatic compression improves the symptoms of severe postthrombotic syndrome (evidence level B) (14). In their recent study, Kahn et al. also recommend intermittent pneumatic compression in patients with moderate to severe postthrombotic syndrome (1).

Because of the lack of evidence of positive effect, and also the possibility of long-term side effects, medical therapy with venoactive drugs (e.g., rutoside) is not recommended $(1,20)$.

Exercise training and physiotherapy aim to improve symptoms, mainly by improving the calf muscle pump function. Two studies have investigated the efficacy of this treatment in comparison with a control group that did not exercise. The exercise group showed improvement of symptoms and quality of life, leg strength, and mobility (21, e8). For this reason the AHA recommends a supervised exercise program (recommendation class IIa, evidence level B) (17).

\section{Surgical treatment of postthrombotic syndrome}

There are no randomized controlled studies of surgical treatment, either in the form of comparison of operative versus conservative treatment or of randomized comparisons between the various surgical treatments. In terms of open and hybrid operations, only small, nonrandomized studies with low patient numbers and variable follow-up have been carried out (evidence level C). With regard to endovascular operations, at least studies with larger patient numbers do exist (Neglén et al., $\mathrm{n}=982$ ), meaning that evidence level B is attained (22).

In patients with severe postthrombotic syndrome, the iliac obstructions should be treated first. Interventions to correct reflux can only succeed if iliocaval outflow is restored $(17,23$, e9).

\section{Open surgical treatment of obstruction/occusion}

In patients with unilateral iliac vein obstruction, Palma and Esperon described a femorofemoral crossover 
Studies of open surgical treatment of postthrombotic syndrome

\begin{tabular}{|c|c|c|c|c|c|c|c|}
\hline Authors (reference) & Year & $\begin{array}{l}\text { Number of } \\
\text { extremities }\end{array}$ & $\begin{array}{l}\text { Follow-up } \\
\text { (months) }\end{array}$ & $\begin{array}{l}\text { Patency rate } \\
(\%)\end{array}$ & $\begin{array}{l}\text { Improvement of symptoms } \\
(\%)\end{array}$ & Transplant material & Operation \\
\hline Palma and Esperon (24) & 1960 & 8 & Up to 36 & n.a. & 88 & Vein & \multirow{7}{*}{ 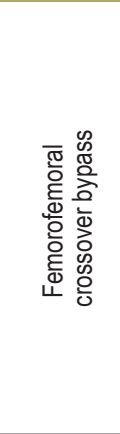 } \\
\hline May (e11) & 1981 & 66 & n.a. & 73 & n.a. & Vein & \\
\hline Husni (e12) & 1983 & 85 & $6-180$ & 70 & 74 & $\begin{array}{l}\text { Vein }(n=83) \\
\text { PTFE }(n=2)\end{array}$ & \\
\hline Halliday et al. (e13) & 1985 & 47 & Up to 216 & 75 & 89 & Vein & \\
\hline AbuRahma et al. (e14) & 1991 & 24 & 66 & 75 & 63 & Vein & \\
\hline Gruss und Hiemer (e10) & 1997 & $\begin{array}{l}19 \\
32\end{array}$ & $\begin{array}{l}\text { n.a. } \\
\text { n.a. }\end{array}$ & $\begin{array}{l}71 \\
85\end{array}$ & 82 & $\begin{array}{l}\text { Vein } \\
\text { PTFE }\end{array}$ & \\
\hline Garg et al. (25) & 2011 & 29 & 60 & 70 & n.a. & $\begin{array}{l}\text { Vein }(n=25) \\
\text { PTFE }(n=4)\end{array}$ & \\
\hline Husfeldt (e15) & 1981 & 4 & $4-30$ & 100 & 100 & PTFE & \multirow{5}{*}{ 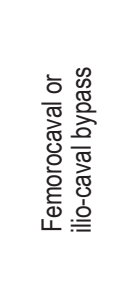 } \\
\hline Dale et al. (e16) & 1984 & 3 & $1-30$ & 100 & 100 & PTFE & \\
\hline Gloviczki et al. (e17) & 1992 & 12 & $1-60$ & 58 & 67 & $\begin{array}{l}\text { PTFE: } 11 \\
\text { Dacron:1 }\end{array}$ & \\
\hline Alimi et al. (e18) & 1997 & 8 & $\begin{array}{c}19.5 \\
\text { (mean) }\end{array}$ & 88 & 88 & PTFE & \\
\hline Garg et al.(25) & 2011 & 17 & 60 & 63 & n.a. & PTFE & \\
\hline
\end{tabular}

n.a., not available; PTFE, polytetrafluoroethylene

bypass using the contralateral great saphenous vein, a long segment of which is mobilized, subcutaneously tunneled to the contralateral side, and anastomosed end-to-side with the common femoral vein on the affected side (24) (Figure 2). If no suitable great saphenous vein is found, ring-reinforced polytetrafluoroethylene prostheses can be used. To prevent bypass occlusion, this procedure is often combined with placement of an arteriovenous anastomosis. In the literature, the patency rate is reported to be $70 \%$ to $85 \%$ (follow-up: 6 to 216 months) (25, e10-e14).

In patients with more extensive venous obstructions (bilateral iliac vein obstruction, involvement of the infrarenal vena cava), femorocaval or iliocaval prosthetic bypass is carried out $(25, \mathrm{e} 15-\mathrm{e} 18)$.

The Table lists all the existing studies on open surgical treatment of postthrombotic syndrome. Based on the existing small studies, the AHA can only give a weak recommendation for the use of these bypasses (recommendation class IIb, evidence level C) (17).

\section{Endovascular treatment of obstruction/occlusion}

In 2000, Neglén et al. published the first study of the technique of percutaneous transfemoral recanalization of the iliac venous outflow tract by means of stent angioplasty (26). Since then, this treatment option has come into wider use. In 2007, Neglén et al. published the largest study so far, with 982 patients $(n=464$ of them with postthrombotic syndrome) in whom they carried out stent angioplasty of the iliac outflow tract. Mortality in the overall group was $0 \%$; among the patients with postthrombotic syndrome, the primary patency rate after 72 months was $57 \%$ and the secondary patency rate was $86 \%$. Ulcer healing was achieved in $58 \%$ of patients. Neglén et al. were able to show a significant improvement in quality of life (22). In other studies of treatment of postthrombotic syndrome using stent angioplasty, primary patency rates of $38 \%$ to $100 \%$ and secondary patency rates of $73 \%$ to $100 \%$ were achieved (follow-up: 9 to 68 months) (27, e19-e27). Complications (chiefly, thrombotic occlusion of the recanalized segment and hematomas at the catheter puncture site) were below $6 \%$ (22). Where recanalization failed, no progression of clinical signs occurred $(22,28)$. The AHA gives a weak recommendation for endovascular treatment (recommendation class IIb, evidence level B) (17).

\section{Technical details}

After venography and passage of the postthrombotically altered segment of the vein with wires and support catheters, the obstruction is dilated. Stent angioplasty is carried out, followed by further dilatation. The stent angioplasty is carried out along the entire postthrombotically altered iliac and caval segments (Figure 3). 

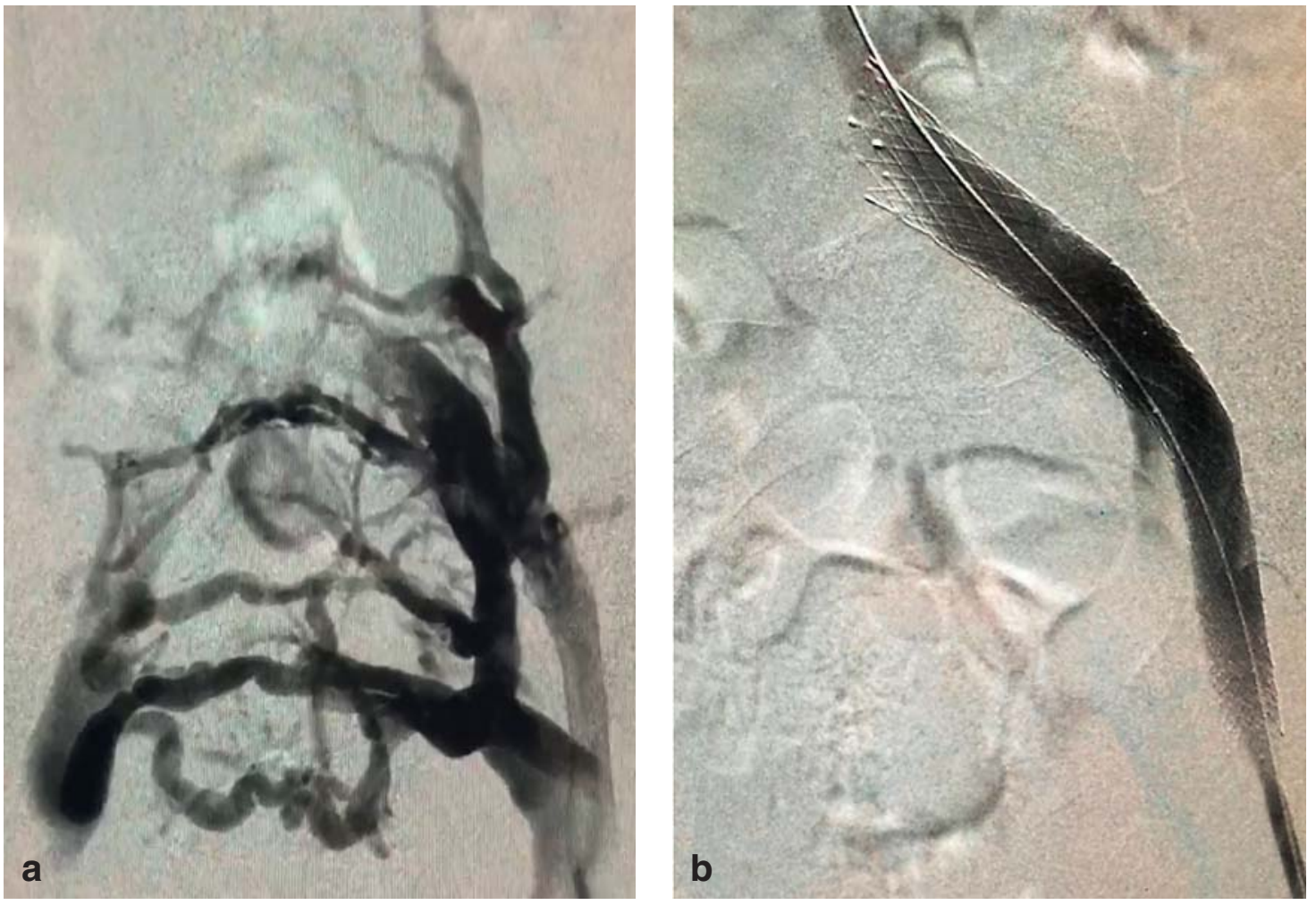

\section{Figure 3:}

Intraoperative venography

a) before recanalization (occlusion of the left pelvic venous outflow tract with demonstration of multiple collaterals)

b) after recanalization (good outflow via the stented left pelvic outflow tract, no collaterals are demonstrated)

\section{Hybrid procedure}

When inflow is obstructed by postthrombotic trabeculae in the region of the common femoral vein, in addition to stent angioplasty, surgical desobliteration (endovenotomy) of the common femoral vein and the ostia of its tributaries, especially the deep femoral vein, must be carried out. This ensures adequate inflow to the recanalized segment of vein and avoids early thrombotic occlusion: after longitudinal venotomy of the common femoral vein, the postthrombotic trabeculae are removed, and the venotomy is closed with a patch plasty. This technique was first published by Comerota et al. ( $n=16$ extremities with obstruction of the iliac veins and the common femoral vein). Mean follow-up time was 26 months. Quality of life and Villalta score improved significantly (29, e28, e29). Gloviczki et al. also achieved good results (e30). To improve inflow, additionally, an arteriovenous fistula can be created between the femoral vein and the superficial femoral vein; the fistula is then closed 6 weeks to 3 months postoperatively, in order to avoid right heart overload (e31-e33). On the basis of the existing studies, according to the AHA, the hybrid procedure may be considered in patients with severe postthrombotic syndrome (recommendation class IIb, evidence level C) (17) (Figure 4).

\section{Contraindications}

In cases where there is insufficient inflow from the periphery due to long-segment postthrombotic obstructions of the femoral and deep femoral veins, iliocaval recanalization is unlikely to succeed and is therefore contraindicated. In addition, patients in whom therapeutic anticoagulation is contraindicated should not undergo recanalization (30).

\section{Peri- and postoperative concomitant treatment}

After recanalization, thrombotic occlusion of the recanalized segment is the most frequent postoperative complication $(1.5 \%$ during the early postoperative period $[<30$ days], $3 \%$ during the later postoperative period) (22). For this reason, adequate therapeutic anticoagulation during the perioperative period is essential $(22,27)$. Anticoagulation treatment should be continued for at least 6 months postoperatively, either with vitamin $\mathrm{K}$ antagonists (target INR: 2.5 to 3.5 ) or with the new oral anticoagulants (NOAC). Early mobilization and compression therapy should also be part of the postoperative treatment regimen $(30,31)$.

\section{New venous stents}

The stents usually employed for arterial stent angioplasty (e.g., Wall stents, nitinol stents) are unsuitable 


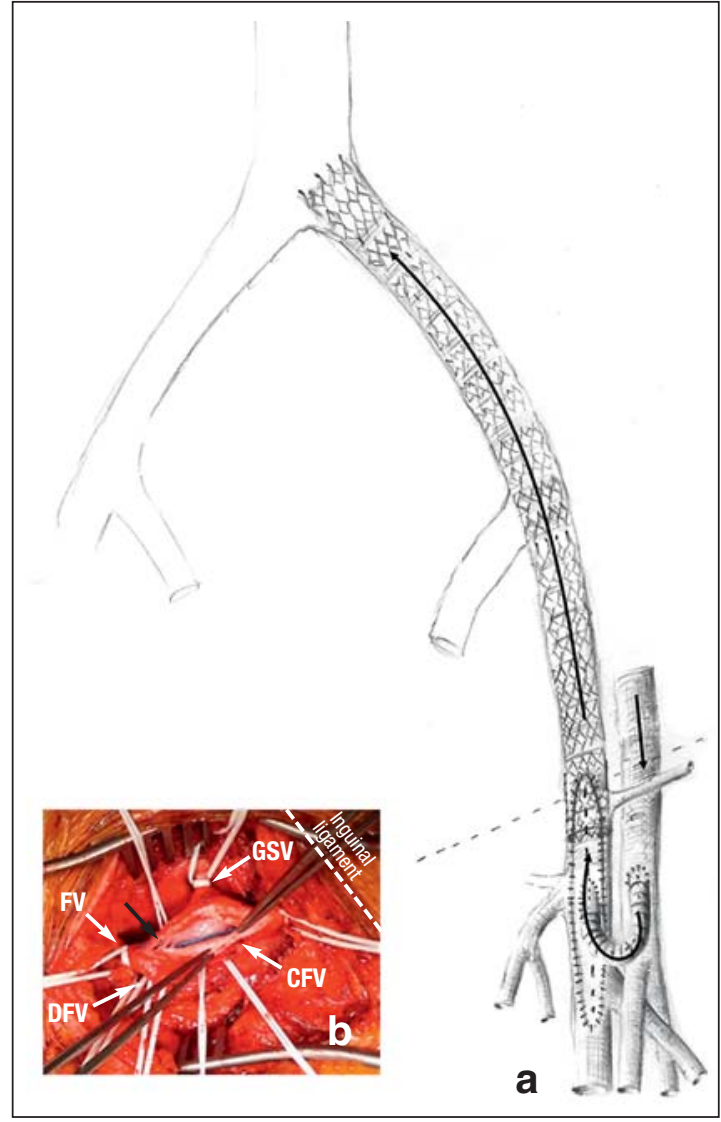

Figure 4: Hybrid surgical procedure

a) Schematic illustration of the hybrid procedure (iliac stent angioplasty, endovenectomy of the common femoral vein with patch plasty plus placement of a loop-shaped arteriovenous fistula (polytetrafluoroethylene prosthesis)

b) Intraoperative site during endovenectomy of the left common femoral vein (status post longitudinal venotomy, guide wire in situ for the subsequent iliac stent angioplasty, evidence of postthrombotic trabeculae, marked with black arrows)

$\mathrm{FV}$, femoral vein; CFV, common femoral vein; DFV, deep femoral vein; GSV, great saphenous vein

for stent angioplasty of a postthrombotically altered vein, as often long segments of the latter are fibrotic and often the vein is externally compressed (e.g., in May-Thurner syndrome). Venous stents with greater radial force have therefore been developed. High flexibility is also required, so that the stents can adapt to the anatomic course of the veins during movement; in the region of the iliac bifurcation, in particular, angulation up to $90^{\circ}$ occurs during sitting $(31,32)$.

\section{Results with venous stents}

From March 2012 to July 2014, we carried out recanalization using venous stents (Sinus Venous Stent, Opti-Med, Ettlingen, Germany) in 40 patients with postthrombotic syndrome. Follow-up time was 5.5 (1 to $18)$ months. Mortality was zero, and primary patency rates after 3, 6, and 12 months were $97 \%, 93 \%$, and $85 \%$. In three patients, rethrombosis occurred; these patients were successfully treated endovascularly. During therapeutic anticoagulation (Marcumar [phenprocoumon]: $n=15$; rivaroxaban: $n=25$ ), five patients experienced minor bleeding not requiring treatment. The mean Villalta score fell postoperatively from 11.5 (2 to $24)$ to 5.0 (0 to 16$)(31,32)$.

\section{Surgical treatment of reflux}

Incompetent venous valves in the common or deep femoral vein can be corrected by valve-reconstructing surgery (internal or external valvuloplasty, extravascular banding of the valve-bearing segment) $(33,34$, e 34 , e35).

Where valves have been irreversibly destroyed, according to AHA recommendations, transplantation of an arm vein or vein transposition can be carried out (IIb, C) $(17,35$, e36).

If, after successful recanalization of the obstructions, symptoms persist due to reflux because of secondary varicosis of the great saphenous vein, thermal ablation of the incompetent great saphenous vein is a possible approach (36, e37). However, no prospective studies have been carried out.

Stripping or ligation of perforating veins that are maintaining an ulcer because of reflux is aimed at alleviating symptoms and healing the ulcer. Only the diseased segments of veins are operated on (e38-e40). Neovalve construction is a potential approach for patients with refractory ulcers $(\mathrm{IIb}, \mathrm{C}),(17,37)$.

\section{Discussion}

Because of low case numbers, heterogeneous patient groups, and differences in treatments, no large randomized studies of operative treatment of postthrombotic syndrome exist of the kind that could provide a basis for clear, evidence-based treatment recommendations. The 2008 guideline of the German Society of Vascular Surgery is now out of date (38). The AHA, in its current guideline published in 2014, gives all operative treatments equally a weak recommendation (IIb) (17). For this reason, all conservative treatment options (compression by medical compression stockings or intermittent pneumatic compression, exercise training, physiotherapy) should be tried first. If severe symptoms of postthrombotic syndrome persist and the patient's quality of life is markedly impaired, especially by venous claudication and/or a venous ulcer that is not healing, indicating that conservative treatment has failed, surgical treatment should be considered. The decision whether to operate, and the choice of procedure, should be made with great care. The decision is made on a case-by-case basis taking account of the severity of the postthrombotic syndrome, the underlying pathology, and the patient's concomitant diseases. Since postthrombotic syndrome is very rarely a threat to life or limb, any operation carried out should 
be the least invasive possible, with the aim of alleviating symptoms and improving quality of life. For this reason, endovascular recanalization appears to be an appropriate form of treatment; if it fails, no progression of symptoms occurs and open surgery remains as a further option $(22,26)$. Because the outcome of both open and endovascular procedures depends on operator expertise, these treatments should be carried out in a specialized vascular center offering the complete range of diagnostic investigations and surgical procedures including both endovascular and open surgery (17). Overall, the recommendations for the treatment of postthrombotic syndrome rest on low level evidence. For definitive evaluation and optimization of treatment, therefore, prospective randomized studies of endovascular therapy of postthrombotic syndrome and optimal stent configuration are needed.

\section{KEY MESSAGES}

- Postthrombotic syndrome occurs in about $20 \%$ to $50 \%$ of patients in whom deep vein thrombosis has been diagnosed, and has considerable socioeconomic consequences.

- The following therapeutic options exist:
a) Conservative treatment
b) Open surgical procedures
c) Endovascular recanalization and hybrid procedures.

- Only when conservative treatment has failed should an invasive procedure be considered.

- Since at present there is insufficient evidence to show any procedure to be superior, the least invasive procedure possible should be employed.

- This suggests that endovascular recanalization may be regarded as the treatment of choice for chronic iliac vein obstruction.

\section{Conflict of interest statement}

Dr. Jalaie has received consultancy fees from 0ptimed. He has been reimbursed for conference, travel, and accommodation costs and received lecture fees from Optimed and Ab Medica.

$\mathrm{Dr}$. Grommes has been reimbursed for conference, travel, and accommodation costs by Ab Medica. He has received lecture fees from Ab Medica and BTG UK. $\mathrm{He}$ has received funding to conduct a clinical trial from Ab Medica.

The remaining authors declare that no conflict of interest exists.

Manuscript received on 24 May 2016, revised version accepted on 1 September 2016.

Translated from the original German by Kersti Wagstaff, MA.

\section{REFERENCES}

1. Kahn SR, Galanaud JP, Vedantham S, Ginsberg JS: Guidance for the prevention and treatment of the post-thrombotic syndrome. J Thromb Thrombolysis 2016; 41: 144-53.

2. Kahn SR, Shrier I, Julian JA, et al.: Determinants and time course of the postthrombotic syndrome after acute deep venous thrombosis. Ann Intern Med 2008; 149: 698-707.
3. Pollack AA, Wood EH: Venous pressure in the saphenous vein at the ankle in man during exercise and changes in posture. J Appl Physiol 1949; 1: 649-62.

4. Hach W: Das arthrogene Stauungssyndrom. Gefäßchirurgie 2003; 8: 227-33.

5. MacDougall DA, Feliu AL, Boccuzzi SJ, Lin J: Economic burden of deep-vein thrombosis, pulmonary embolism, and post-thrombotic syndrome. Am J Health Syst Pharm 2006; 63: S5-15.

6. Brandjes DP, Buller HR, Heijboer $\mathrm{H}$, et al.: Randomised trial of effect of compression stockings in patients with symptomatic proximalvein thrombosis. Lancet 1997; 349: 759-62.

7. Ginsberg JS, Hirsh J, Julian J, et al.: Prevention and treatment of postphlebitic syndrome: results of a 3-part study. Arch Intern Med 2001; 161: 2105-9.

8. Villalta S, Bagatella P, Piccioli A, Lensing A, Prins M, Prandoni P: Assessment of validity and reproducibility of a clinical scale for the post-thrombotic syndrome. Haemostasis 1994; 24: 158a.

9. Arnoldussen CW, de Graaf R, Wittens $\mathrm{CH}$, de Haan MW: Value of magnetic resonance venography and computed tomographic venography in lower extremity chronic venous disease. Phlebology 2013; 28: 169-75.

10. Tick LW, Doggen CJ, Rosendaal FR, et al.: Predictors of the postthrombotic syndrome with non-invasive venous examinations in patients 6 weeks after a first episode of deep vein thrombosis. J Thromb Haemost 2010; 8: 2685-92.

11. Kahn SR, Ginsberg JS: Relationship between deep venous thrombosis and the postthrombotic syndrome. Arch Intern Med 2004; 164: 17-26.

12. Chen JT, Comerota AJ: Detecting the association between residual thrombus and post-thrombotic classification of chronic venous disease with range regression. Rev Recent Clin Trials 2012; 7 : 329-34.

13. Wienert V, Gerlach H, Gallenkemper G, et al.: Leitlinie: Medizinischer Kompressionsstrumpf (MKS). Phlebologie 2006; 35: 315-20.

14. Wienert V, Partsch H, Gallenkemper G, et al.: Leitlinie: Intermittierende pneumatische Kompression (IPK oder AlK) Entwicklungsstufe S2. Phlebologie 2005; 34: 176-80.

15. Frulla M, Marchiori A, Sartor D, Mosena L, Tormene D, Hartman L: Elastic stockings, hydroxyethylrutosides or both for the treatment of post-thrombotic syndrome. Thromb Haemost 2005; 93: 183-5.

16. Kolbach DN, Sandbrink MW, Neumann HA, Prins MH: Compression therapy for treating stage I and II (Widmer) post-thrombotic syndrome. Cochrane Database Syst Rev 2003: CD004177.

17. Kahn SR, Comerota AJ, Cushman M, et al.: The postthrombotic syndrome: evidence-based prevention, diagnosis, and treatment strategies: a scientific statement from the American Heart Association. Circulation 2014; 130: 1636-61.

18. Kahn SR, Shapiro S, Wells PS, et al.: Compression stockings to prevent post-thrombotic syndrome: a randomised placebo-controlled trial. Lancet 2014; 383: 880-8.

19. O’Meara S, Cullum N, Nelson EA, Dumville JC: Compression for venous leg ulcers. Cochrane Database Syst Rev 2012; 11: CD000265.

20. Morling JR, Yeoh SE, Kolbach DN: Rutosides for prevention of postthrombotic syndrome. Cochrane Database Syst Rev 2015.

21. Kahn SR, Shrier I, Shapiro S, et al.: Six-month exercise training program to treat post-thrombotic syndrome: a randomized controlled two-centre trial. CMAJ 2011; 183: 37-44.

22. Neglén P, Hollis KC, Olivier J, Raju S: Stenting of the venous outflow in chronic venous disease: long-term stent-related outcome, clinical, and hemodynamic result. J Vasc Surg 2007; 46: 979-90.

23. Raju S, Darcey R, Neglen P: Unexpected major role for venous stenting in deep reflux disease. J Vasc Surg 2010; 51: 401-8.

24. Palma EC, Esperon R: Vein transplants and grafts in the surgical treatment of the postphlebitic syndrome. J Cardiovasc Surg 1960; 1: 94-107.

25. Garg N, Gloviczki P, Karimi KM, et al.: Factors affecting outcome of open and hybrid reconstructions for nonmalignant obstruction of iliofemoral veins and inferior vena cava. J Vasc Surg 2011; 53: 383-93. 
26. Neglén P, Berry MA, Raju S: Endovascular surgery in the treatment of chronic primary and post-thrombotic iliac vein obstruction. Eur $\mathrm{J}$ Vasc Endovasc Surg 2000; 20: 560-71.

27. Hartung 0, Loundou AD, Barthelemy P, Arnoux D, Boufi M, Alimi YS: Endovascular management of chronic disabling ilio-caval obstructive lesions: long-term results. Eur J Vasc Endovasc Surg 2009; 38: 118-24.

28. Neglen P, Tackett TP, Jr., Raju S: Venous stenting across the inguinal ligament. J Vasc Surg 2008; 48: 1255-61.

29. Comerota AJ, Charles J, Tegtmeyer MD: Annual Lecture: Contemporary concepts in the management of acute iliofemoral DVT and chronic post-thrombotic iliofemoral venous obstruction - ISET 2013 $-25^{\text {th }}$ annual international symposium on endovascular therapy. www.prolibraries.com/player/?libname=iset\&sessionlD=2961\# (last accessed on 11 October 2016).

30. Jalaie H, Arnoldussen C, Barbati M, et al.: What predicts outcome after recanalization of chronic venous obstruction: hemodynamic factors, stent geometry, patient selection, anticoagulation or other factors? Phlebology 2014; 29: 97-103.

31. Jalaie H, Schleimer K, Barbati ME, et al.: Interventional treatment of postthrombotic syndrome. Gefässchirurgie 2016;21(Suppl 2): 37-44.

32. de Wolf MA, de Graaf R, Kurstiens RL, Penninx S, Jalaie H, Wittens $\mathrm{CH}$ : Short-term clinical experience with a dedicated venous nitinol stent: initial results with the sinus-venous stent. Eur J Vasc Endovasc Surg 2015; 50: 518-26.

33. Kistner RL: Surgical repair of venous valve. Straub Clin Proc 24 1968: 41-3.

34. Masuda EM, Kistner RL: Long-term results of venous valve reconstruction: a four- to twenty-one-year follow-up. J Vasc Surg 1994; 19: 391-403.
35. Taheri SA, Elias SM, Yacobucci GN, Heffner R, Lazar L: Indications and results of vein valve transplant. J Cardiovasc Surg 1986; 27: 163-8.

36. Neglen P, Hollis KC, Raju S: Combined saphenous ablation and iliac stent placement for complex severe chronic venous disease. J Vasc Surg 2006; 44: 828-33.

37. Lugli M, Guerzoni S, Garofalo M, Smedile G, Maleti 0: Neovalve construction in deep venous incompetence. J Vasc Surg 2009; 49: 156-62.

38. Diagnostik und Therapie des postthrombotischen Syndroms (einschließlich Ulcus cruris) (S2). Leitlinien zu Diagnostik und Therapie in der Gefäßchirurgie. Berlin, Heidelberg: Springer 2008; 141-6.

\section{Corresponding author:}

PD Dr. med. Karina Schleimer

Uniklinik RWTH Aachen

Pauwelsstr. 30, 52074 Aachen, Germany

kschleimer@ukaachen.de 


\section{Supplementary material to:}

\section{The Treatment of Post-thrombotic Syndrome}

The Role of Endovascular Recanalization in Chronic lliac Vein Obstruction

by Karina Schleimer, Mohammad Esmaeil Barbati, Alexander Gombert, Volker Wienert, Jochen Grommes, and Houman Jalaie

Dtsch Arztebl Int 2016; 113: 863-70. D0l: 10.3238/arztebl.2016.0863

\section{eREFERENCES}

e1. Kahn SR, Ginsberg JS: The post-thrombotic syndrome: current knowledge, controversies, and directions for future research. Blood Rev 2002; 16 : 155-65.

e2. Meissner MH, Moneta G, Burnand K, et al.: The hemodynamics and diagnosis of venous disease. J Vasc Surg 2007; 46 Suppl S: 4s-24s.

e3. Baldwin MJ, Moore HM, Rudarakanchana N, Gohel M, Davies AH: Postthrombotic syndrome: a clinical review. J Thromb Haemost 2013; 11: 795-805.

e4. Kahn SR, Kearon C, Julian JA, et al.: Predictors of the post-thrombotic syndrome during long-term treatment of proximal deep vein thrombosis. J Thromb Haemost 2005; 3: 718-23.

e5. Prandoni P, Lensing AW, Cogo A, et al.: The long-term clinical course of acute deep venous thrombosis. Ann Intern Med 1996; 125: 1-7.

e6. Comerota AJ, Grewal N, Martinez JT, et al.: Postthrombotic morbidity correlates with residual thrombus following catheter-directed thrombolysis for iliofemoral deep vein thrombosis. J Vasc Surg 2012; 55: 768-73.

e7. Hull RD, Marder VJ, Mah AF, Biel RK, Brant RF: Quantitative assessment of thrombus burden predicts the outcome of treatment for venous thrombosis: a systematic review. Am J Med 2005; 118: 456-64.

e8. Padberg FT, Jr., Johnston MV, Sisto SA: Structured exercise improves calf muscle pump function in chronic venous insufficiency: a randomized trial. J Vasc Surg 2004; 39: 79-87.

e9. Henke PK, Comerota AJ: An update on etiology, prevention, and therapy of postthrombotic syndrome. J Vasc Surg 2011; 53: 500-9.

e10. Gruss J, Hiemer W: Bypass procedures for venous obstruction: Palma and May-Husni bypasses, Raju perforator bypass, prosthetic bypasses, primary and adjunctive arteriovenous fistulae. Surgical Management of Venous Diseases Baltimore, Md: Williams \& Wilkins 1997; 289-305.

e11. May R: The Palma operation with Gottlob's endothelium preserving suture. In: May R, Weber J, eds.: Pelvic and abdominal veins: progress in diagnostics and therapy. Excerpta Medica, Amsterdam; 1981: 192-7.

e12. Husni EA: Reconstruction of veins: the need for objectivity. J Cardiovasc Surg 1983; 24: 525-8.

e13. Halliday P, Harris J, May J: Femoro-femoral crossover grafts (Palma operation): a long-term follow-up study. Surgery of the veins. Grune \& Stratton, Orlando 1985: 241-54

e14. AbuRahma AF, Robinson PA, Boland JP: Clinical, hemodynamic, and anatomic predictors of long-term outcome of lower extremity venovenous bypasses. J Vasc Surg 1991; 14: 635-44.

e15. KJ Husfeldt: Venous replacement with gore-tex prosthesis: experimental and first clinical results: In : May R, Weber J, eds.: Pelvic and abdominal veins: progress in diagnostics and therapy. Amsterdam: Excerpta Medica 1981; 249-58.

e16. Dale WA, Harris J, Terry RB: Polytetrafluoroethylene reconstruction of the inferior vena cava. Surgery 1984; 95: 625-30.

e17. Gloviczki P, Pairolero PC, Toomey BJ, et al.: Reconstruction of large veins for nonmalignant venous occlusive disease. J Vasc Surg 1992; 16: 750-61.

e18. Alimi YS, DiMauro P, Fabre D, Juhan C: Iliac vein reconstructions to treat acute and chronic venous occlusive disease. J Vasc Surg 1997; 25: 673-81.

e19. Blättler W, Blättler IK: Relief of obstructive pelvic venous symptoms with endoluminal stenting. J Vasc Surg 1999; 29: 484-8.

e20. Hood DB, Alexander JQ: Endovascular management of iliofemoral venous occlusive disease. Surg Clin North Am 2004; 84: 1381-96.

e21. Knipp BS, Ferguson E, Williams DM, et al.: Factors associated with outcome after interventional treatment of symptomatic iliac vein compression syndrome. J Vasc Surg 2007; 46: 743-9. e22. Nazarian GK, Bjarnason H, Dietz CA Jr, Bernadas CA, Hunter DW: lliofemoral venous stenoses: effectiveness of treatment with metallic endovascular stents. Radiology 1996; 200: 193-9.

e23. Oguzkurt L, Tercan F, Ozkan U, Gulcan 0: lliac vein compression syndrome: outcome of endovascular treatment with long-term follow-up. Eur J Radiol 2008; 68: 487-92.

e24. O'Sullivan GJ, Semba CP, Bittner CA, et al.: Endovascular management of iliac vein compression (May-Thurner) syndrome. J Vasc Interv Radiol 2000; 11: 823-36.

e25. Raju S, Hollis K, Neglen P: Obstructive lesions of the inferior vena cava: clinical features and endovenous treatment. J Vasc Surg 2006; 44: 820-7.

e26. Razavi MK, Hansch EC, Kee ST, Sze DY, Semba CP, Dake MD: Chronically occluded inferior venae cavae: endovascular treatment. Radiology 2000; 214: 133-8.

e27. te Riele WW, Overtoom TT, van den Berg JC, van de Pavoordt ED, de Vries JP: Endovascular recanalization of chronic long-segment occlusions of the inferior vena cava: midterm results. J Endovasc Ther 2006; 13: 249-53.

e28. Comerota AJ, Grewal NK, Thakur S, Assi Z: Endovenectomy of the common femoral vein and intraoperative iliac vein recanalization for chronic iliofemoral venous occlusion. J Vasc Surg 2010; 52: 243-7.

e29. Vogel D, Comerota AJ, Al-Jabouri M, Assi Zl: Common femoral endovenectomy with iliocaval endoluminal recanalization improves symptoms and quality of life in patients with postthrombotic iliofemoral obstruction. J Vasc Surg 2012; 55: 129-35.

e30. Gloviczki P, Kalra M, Duncan AA, Oderich GS, Vrtiska TJ, Bower TC: Open and hybrid deep vein reconstructions: to do or not to do? Phlebology 2012; 27: $103-6$.

e31. Eklof B: Temporary arteriovenous fistula in reconstruction of iliac vein obstruction using PTFE grafts. Controversies in the management of venous disorders, London, UK: Butterworths 1989: 280-90.

e32. Ijima H, Kodama M, Hori M: Temporary arteriovenous fistula for venous reconstruction using synthetic graft: a clinical and experimental investigation. J Cardiovasc Surg 1985; 26: 131-6.

e33. Okadome K, Muto Y, Eguchi H, Kusaba A, Sugimachi K: Venous reconstruction for iliofemoral venous occlusion facilitated by temporary arteriovenous shunt. Long-term results in nine patients. Arch Surg 1989; 124: 957-60.

e34. Kistner RL: Surgical technique of external venous valve repair. Straub Found Proc 1990; 55: 15-6.

e35. Us M, Basaran M, Sanioglu S, et al.: The use of external banding increases the durability of transcommissural external deep venous valve repair. Eur J Vasc Endovasc Surg 2007; 33: 494-501.

e36. Taheri SA, Lazar L, Elias S, Marchand P, Heffner R: Surgical treatment of postphlebitic syndrome with vein valve transplant. Am J Surg 1982; 144: 221-4.

e37. Nayak L, Hildebolt CF, Vedantham S: Postthrombotic syndrome: feasibility of a strategy of imaging-guided endovascular intervention. J Vasc Interv Radiol 2012; 23: 1165-73.

e38. Bond RT, Cohen JM, Comerota A, Kahn SR: Surgical treatment of moderateto-severe post-thrombotic syndrome. Ann Vasc Surg 2013; 27: 242-58.

e39. Kleinspehn E, Kühme T, Atlihan G, Gebhardt C, Debus ES: Open surgical procedures for the treatment of post thrombotic syndrome (PTS). Gefässchirurgie 2016; 21: 64-5.

e40. Kalra M, Gloviczki P, Noel AA, et al.: Subfascial endoscopic perforator vein surgery in patients with post-thrombotic venous insufficiency-is it justified? Vasc Endovascular Surg 2002; 36: 41-50. 